\title{
A (Limited) Defence of Priorianism
}

\author{
Daniel Deasy (School of Philosophy, University College Dublin) \\ Forthcoming in Inquiry
}

\begin{abstract}
This paper defends Priorianism, a theory in the philosophy of time which combines three theses: first, that there is a metaphysical distinction between the present time and non-present times; second, that there are temporary propositions, that is, propositions that change in truthvalue simpliciter over time; and third, that there is change over time only if there are temporary propositions. Priorianism is accepted by many Presentists, Growing Block Theorists, and Moving Spotlight Theorists. However, it is difficult to defend the view without appealing to premises that those who reject the view find controversial. My aim in this paper is to defend Priorianism in a way that largely avoids appealing to such premises. I do three things: first (Section 1), I describe the component theses of Priorianism and the relations between them. Next (Section 2), I show how Priorians can respond to the argument that the B-theory implies that there are temporary propositions, and therefore satisfies the Priorian condition for there being change over time. Finally (Section 3), I defend the Priorian thesis that there is change over time only if there are temporary propositions against an alternative principle of change defended by Ross Cameron (The Moving Spotlight, 2015).
\end{abstract}

\section{Key words}

Time; Change; Temporalism; Arthur Prior; B-theory 


\section{Introduction}

There is an important debate in the philosophy of time between those who accept the theses of Temporalism (informally, the view that some propositions change in truth-value simpliciter over time) and Temporal Disparity (the view that there is a metaphysical distinction between the present time and non-present times), and those who reject them. For example, Presentists such as Markosian (2004), Prior (1968), and Rasmussen (2012); Growing Blockers such as Forbes (2016) and Forrest (2004); and Moving Spotlighters such as Cameron (2015) accept both Temporalism and Temporal Disparity, whereas B-theorists such as Quine (1960), Mellor (1998) and Sider (2001) seem to reject them. ${ }^{1}$ Moreover, following Prior (1968), many of those who accept both Temporalism and Temporal Disparity also accept the view that I call Priorian Change, according to which the truth of Temporalism is a necessary condition for there being change over time. I call such philosophers Priorians.

In this paper, I provide a limited defence of Priorianism. I call it a 'limited' defence for two reasons: first, because my focus in what follows is on defending Temporalism and Priorian Change rather than Temporal Disparity. There are two reason for this: first, as we shall see below in $\S 1$, Priorians disagree amongst themselves as to what exactly it is that metaphysically distinguishes the present time from non-present times. This makes it difficult to provide a unified treatment of Temporal Disparity. Second, many of those who accept Temporal Disparity accept it on the grounds that our experience tells us that there is a fundamental distinction between present and non-present events, and therefore a fundamental distinction between the present time and non-present times. ${ }^{2}$ It would be impossible to do justice to such 'arguments from experience' for Temporal Disparity here: they deserve a

\footnotetext{
${ }^{1}$ I don't claim that all of these works contain explicit defences of the relevant theses, but rather that the views they defend can reasonably be interpreted as views on which the relevant theses are true.

${ }^{2}$ Skow (2015, Chapters 11 and 12) describes a number of 'arguments from experience' for the conclusion that the present time is metaphysically privileged. See also Spolaore \& Torrengo (2019) for the development and rejection of such an argument.
} 
dedicated discussion.

The second reason I call my defence 'limited' is because I do not attempt to provide original arguments in favour of Temporalism and Priorian Change. The reason is that most philosophers who accept those theses accept them on grounds that are not very compelling to those who already reject them. In particular, many of those who accept Temporalism simply accept it on the basis of its instances: ${ }^{3}$ for example, given that I was standing half an hour ago and am now sitting, the proposition that I am sitting is sometimes but not always true. But of course, those who reject Temporalism will argue that its alleged instances are not really instances at all. And those who accept Priorian Change typically accept it is a basic principle: they simply hold that if the facts never change, nothing changes. ${ }^{4}$

So, rather than attempting to provide original arguments in favour of Temporalism and Priorian Change, I do three things: first (§1), I carefully describe Temporalism, Temporal Disparity, and Priorian Change. My aim here is to advance the dialectic between Priorians and their opponents by (i) setting out the three Priorian theses in clear and (relatively) unambiguous terms, and (ii) describing some of the important connections between them. Next (§2), I defend the Priorian argument that given that the B-theory implies the falsehood of Temporalism, the B-theory implies (given Priorian Change) that nothing ever changes. I do this by showing how Priorians can respond to the argument that the B-theory is, in fact, a Temporalist view. It is important to note that my aim in this section is not to convince committed B-theorists that their view implies that nothing ever changes. Rather, my aim is to describe what I take to be the best available Priorian response to the argument that the Btheory implies Temporalism. As above, this serves to advance the dialectic between Priorians and their (B-theoretic) opponents. However, it also contributes to a defence of Priorianism: a

\footnotetext{
${ }^{3}$ This seems to be the case for Prior $(1968,11)$, for example.

${ }^{4}$ Again, see Prior $(1968,9)$.
} 
central motivation for many Priorians is to defend a 'dynamic' theory of time and change, in contrast to the B-theorist's 'static' theory of time and change. If the B-theory turned out to be as 'dynamic' as Priorianism, this particular motivation would be lost. I show how Priorians can try to maintain their claim that in contrast to the B-theory, their view is one on which there is 'dynamic' change. ${ }^{5}$ Finally ( $\left.§ 3\right)$, I defend Priorian Change. As mentioned above, I do not do so by providing an original argument in favour of the view. Rather, I argue against a recent alternative to Priorian Change arising from Ross Cameron's (2015) influential defence of (a version of) the Moving Spotlight Theory (MST). In particular, I argue that Cameron's reliance on a stronger alternative to Priorian Change leads to serious difficulties for his own view; difficulties that can be avoided by an acceptance of Priorian Change. I also argue that given an acceptance of Priorian Change, Cameron can argue that Deasy's (2015) rival version of MST is (unlike Cameron's MST) a view according to which nothing ever changes.

\section{Priorianism}

I begin by describing Priorianism. As mentioned above, at the heart of the view are two theses: Temporalism and Temporal Disparity. Let us consider each in turn. First, Temporalism:

Temporalism: For some $p$, sometimes $p$ and sometimes not- $p$

$$
(\exists p(\mathrm{~S} p \wedge \mathrm{S} \neg p))
$$

Temporalism can be understood informally as the thesis that there are temporary propositions: that is, propositions that are sometimes true and sometimes false. An example of a temporary proposition is $<\mathrm{I}$ am sitting $>^{6}-$ it is true now, but it was false a few minutes ago when I was

\footnotetext{
${ }^{5}$ As an anonymous referee pointed out to me, some philosophers have argued that Priorian views fail to secure 'dynamic' change: see e.g. Deng (2013); Fine (2005); Leininger (2015); Lipman (2018); and Skow (2015). Unfortunately, limitations of space mean that it is not possible to consider these arguments here.

${ }^{6} \operatorname{Read}$ ' $\langle\varphi>$ ' as 'the proposition that $\varphi$ '.
} 
making tea. In contrast, $<\mathrm{I}$ am sitting at $u>$ (where ' $u$ ' names this time) is plausibly a permanent proposition: given that it is true, it is always true, and if it were false, it would always be false. ${ }^{7}$ After all, if I am sitting at this time then for any time $t$, at $t$, I am sitting at this time - just as, given that there are Beefeaters in London, wherever one is, there are Beefeaters in London. ${ }^{8,9}$ It is important to note that Temporalism is consistent with the view that there are no such things as propositions, despite the informal gloss on the thesis provided above. In particular, Prior (1971, Chapter 3) argues that languages containing higher-order quantification - e.g. quantification into predicate or sentence position - can be understood otherwise than by translation into languages that do not, and therefore that higher-order quantification need not be interpreted as equivalent to e.g. first-order 'objectual' quantification over abstracta such as (monadic or polyadic) properties or propositions. ${ }^{10}$ In that case, Temporalism can be interpreted as involving irreducibly higher-order quantification, rather than implicit first-order quantification over propositions. ${ }^{11}$ Let us call Temporalism interpreted as involving irreducibly higher-order quantification Sentential Temporalism. We can then distinguish Sentential Temporalism - acceptance of which is consistent with the view that there are (quantifying at the first-order) no propositions - from Propositional Temporalism, the view that there are (quantifying at the first-order)

\footnotetext{
${ }^{7}$ The claim here is not that every 'time-specific' proposition (i.e. every proposition about a particular time) is permanent. For example, Barlassina \& Del Prete (2015) argue that $<$ Lance Armstrong won the Tour de France in $2000>$ has changed in truth-value over the past two decades, and is therefore a temporary proposition. ${ }^{8}$ Some philosophers posit a second 'time-like' dimension - call it hypertime - and allow that time-specific propositions such as $<\mathrm{I}$ am sitting at $u>$ can have different truth-values relative to different hypertimes (even if they have the same truth-value relative to every time). Such propositions would be permanent but also hypertemporary. (Thank you to an anonymous referee for drawing my attention to this point.)

${ }^{9}$ The distinction between temporary and permanent propositions does not map exactly onto the distinction between 'tensed' and 'tenseless' sentences. For example, whereas the tensed sentence 'It is raining in New York' may be taken to express a temporary proposition, the tensed sentence 'It is now raining in New York' plausibly expresses a permanent proposition (given the standard tense-logical principle that what is now the case is always now the case). (Thank you to an anonymous referee for drawing my attention to this point.)

${ }^{10}$ As well as Prior (1971, Chapter 3), see e.g. Bostock (2004); Frege (1879); Dorr (2016, §4); Jones (2018; 2019); Rayo \& Yablo (2001); and Williamson (2003).

${ }^{11}$ Or, indeed, as involving implicit first-order quantification over linguistic entities such as predicates or sentences, as on the 'substitutional' interpretation of higher-order quantifiers. See e.g. Marcus (1961) for an introduction to substitutional quantification.
} 
propositions that are sometimes true and sometimes false:

Propositional Temporalism: For some $x, x$ is a proposition, and sometimes $x$ is true, and sometimes $x$ is false $(\exists x(\operatorname{Proposition}(x) \wedge \mathrm{S} T r u e(x) \wedge \mathrm{S} \neg \operatorname{True}(x)))$

In this paper, I sometimes speak about Temporalism as if it is equivalent to Propositional Temporalism, as it is difficult to express Temporalism in ordinary language without resorting to talk of propositions - as Prior $(1971,37)$ notes, 'forms like "For some $\mathrm{p}$, p" are not idiomatic English, perhaps not even idiomatic Indo-European'. However, bear in mind as mentioned above that this is merely an informal presentation of the thesis: I intend to remain officially neutral on the question of whether Temporalism should be interpreted as equivalent to Sentential Temporalism or Propositional Temporalism. (As we shall see in $\S 2$ below, the difference between the two interpretations matters.)

Next, we turn to Temporal Disparity:

Temporal Disparity: There is a metaphysical distinction between the present time and non-present times

Temporal Disparity can be thought of as a thesis concerning this time $u$ : namely, that $u$ 's being present metaphysically distinguishes it from every other time. Temporal Disparity does not imply that the property of being present is a metaphysically fundamental property: there is disagreement among those who accept Temporal Disparity as to what metaphysically distinguishes $u$ from every other time. For example, some Presentists (according to whom everything is present) hold that there is exactly one time (although which time there is 
changes), and therefore the metaphysical specialness of $u$ consists in nothing more than its being something. Other Presentists hold that there are past, present, and future times, where times are instant-propositions: maximal, consistent, sometime-true propositions. ${ }^{12}$ On this view, the metaphysical specialness of $u$ consists in its being the true time (all other times are false, but were or will be true). Growing Blockers (according to whom only the past and present are real) typically hold that the metaphysical specialness of $u$ consists in its being the time than which there is no later: informally, 'the leading edge of the growing block'. ${ }^{13}$ And Moving Spotlighters (according to whom the past, present and future are all real) typically hold that the metaphysical specialness of $u$ consists in its possessing the fundamental property of presentness: informally, being 'the time on which the spotlight of presentness shines'. ${ }^{14}$

Temporalism and Temporal Disparity form a natural package: in particular, many of those who defend Temporal Disparity also defend Temporalism, and vice versa. ${ }^{15}$ Indeed, Priorians can argue that Temporal Disparity implies and is implied by Temporalism. For example, suppose one holds that there is some metaphysically special property $G$ possessed by this time $u$ in virtue of which $u$ is present (for example, $G$ might be the property of being true, or being the leading edge of the growing block). In that case, Priorians can argue that unless one holds that $<u$ is $G>$ is temporary, it is always the case that this time is present, and therefore in that sense presentness is 'stuck' at this time. In the other direction, suppose that

\footnotetext{
12 See e.g. Markosian (2004), Prior (1968), and Rasmussen (2012).

${ }^{13}$ See e.g. Forbes (2016) and Forrest (2004).

${ }^{14}$ Deasy (2015) defends this sort of 'traditional' Moving Spotlight Theory; Cameron (2015) does not. Rather, according to Cameron, this time $u$ is present in virtue of being the unique time $t$ such that for all $x, x$ 's age at $t$ is $x$ 's age simpliciter (where ages are fundamental temporary properties of objects).

15 There are exceptions, however. In particular, although he ultimately rejects the view, Skow's $(2015, \S 4.3)$ 'MST-Time' combines Temporal Disparity with an apparent rejection of Temporalism. Skow (ibid, 67) writes: 'When I introduced MST-Supertime I discussed the objection that MST-Supertime does not contain objective becoming because in it time does not undergo robust change. The same objection could be made against MSTTime.' Given that for Skow, a theory $T$ implies that time 'undergoes robust change' just in case $T$ implies Temporalism, this seems to be an admission by Skow that MST-Time does not imply Temporalism. Similarly, Deasy (2015) defends a version of the Moving Spotlight Theory that implies Temporal Disparity but does not clearly imply Temporalism (see $§ 3$ below).
} 
Temporalism is true. In that case, Priorians can argue there must be a unique time $t$ such that for any $p, p$ is true at $t$ iff $p$ is true simpliciter - informally, a unique time at which truth simpliciter and truth-at-a-time 'line up'. Call such a time accurate. ${ }^{16}$ Plausibly, if there is a unique accurate time $t, t$ is the present time. But in that case, given that accuracy is a metaphysically special property, there is a metaphysical distinction between the present time and non-present times. ${ }^{17}$

Priorians combine Temporalism and Temporal Disparity with the view that the truth of Temporalism is a necessary condition for there being change over time. For example, here is Prior $(1968,9)$ :

To say that a change has occurred is to say at least this much: that something which was the case formerly is not the case now. That is, it is at least to say that for some sentence p we have 'It was the case that $\mathrm{p}$, and it is not the case that $\mathrm{p}^{\text {, }}{ }^{18}$

According to Prior, a change has occurred only if for some $p$, it was the case that $p$ and it is not the case that $p(\exists p(\mathrm{P} p \wedge \neg p))$. Generalising, we can say that change sometimes occurs i.e. there is change over time - only if for some $p$, it is sometimes the case that $p$ and sometimes the case that not- $p$, i.e. only if Temporalism is true. Call this thesis Priorian Change:

\footnotetext{
${ }^{16}$ Following Dorr (Counterparts MS).

${ }^{17}$ Opponents of Priorianism may respond here by arguing that the fact that there are temporary propositions conceived by them as propositions that bear the (permanent) true-at relation to some but not all times - does not imply that there is an accurate time. Whether this response is successful turns on the important question of what exactly it is for a proposition to be 'temporary'. I return to this important question in $\S 2$ below.

${ }^{18}$ Prior's use of the expression 'for some sentence $p$ ' here is, I think, an unfortunate slip, as it gives the unhelpful impression that for Prior, Temporalism is to be interpreted as involving first-order quantification over sentences rather than higher-order quantification into sentence position. However, that would be very surprising given Prior's clear commitment to irreducibly higher-order quantification: see especially Prior (1971, Chapter $3)$.
} 
Priorian Change: There is change over time only if Temporalism is true

Why accept Priorian Change? As mentioned above in $\S 0$, it is not clear that there are any non-question-begging arguments for the view, in the sense of arguments whose premises are likely to be accepted by those who already reject it. Those such as Prior who accept it simply judge that things change only if the facts change; or better yet, that things change only if reality changes. Priorian Change expresses this basic judgement. Finally, given that there is change over time, Priorian Change implies Temporalism; and as we saw above, according to Priorians, Temporalism implies Temporal Disparity. It follows that for Priorians, it is enough to be a Priorian to accept Priorian Change.

\section{Temporalism and the B-theory}

Unlike Presentists, Growing Block Theorists, and Moving Spotlighters, B-theorists according to whom 'time is a dimension just like the three spatial dimensions', 'presentness is merely relative', and 'change is mere variation across time' - appear to reject Temporalism and Temporal Disparity in favour of Atemporalism and Temporal Parity:

Atemporalism: For any $p$, if $p$ then always $p$

$(\forall p(p \rightarrow \mathrm{A} p))$

Temporal Parity: There is no metaphysical distinction between the present time and non-present times

For Priorians, the fact (if it is a fact) that the B-theory implies Atemporalism provides an obvious reason to reject the view: given Priorian Change, it follows that given the B-theory, 
nothing ever changes, and therefore reality is 'static'. But of course, things do change; therefore, the B-theory is false. In other words, Priorians can argue against the B-theory as follows:

(1) There is change over time only if Temporalism is true (Priorian Change)

(2) If the B-theory is true then Temporalism is false

(3) There is change over time

Therefore

(c) The B-theory is false

Of course, there are other ways in which Priorians can argue against the B-theory. For example, they can argue that given that there is a metaphysical distinction between the present time and non-present times, the B-theory is false. And Presentist Priorians can argue that given that the B-theory implies that there are (quantifying unrestrictedly) wholly nonpresent things such as dodos, the B-theory is false. ${ }^{19}$ However, my interest here is in the argument against the B-theory from Priorian Change, for two reasons: first, it is a matter of controversy whether that argument is successful, and in particular, whether premise (2) above is true. Therefore, there is (I think) greater philosophical interest in discussing that argument. Second, we saw above in $\S 1$ that from the Priorian perspective, Priorian Change plausibly

\footnotetext{
${ }^{19}$ See e.g. Zimmerman $(2008,221)$, who writes: 'My reason for believing the A-theory is utterly banal[...]: it is simply part of commonsense that the past and future are less real than the present.'
} 
implies both Temporalism and Temporal Disparity. It follows that unlike the other arguments against the B-theory just mentioned, the argument from Priorian Change is one that (from a Priorian perspective) cannot be made by non-Priorians.

How would B-theorists respond to the argument from Priorian Change? Some Btheorists may reject premise (1) - i.e. Priorian Change - on the grounds that change over time consists in nothing more than (permanent) variation along the temporal dimension, which is consistent with the truth of Atemporalism. But for Priorians, the identification of change with (permanent) variation along the temporal dimension is like the identification of contingency with (necessary) variation between maximal interrelated spatiotemporal systems - it is simply a misidentification of one sort of phenomenon with another.

What about premise (2) - is it really the case that the B-theory implies Atemporalism? Some B-theorists may reject premise (2) on the grounds that, in fact, their view implies Temporalism. For example, a B-theorist could argue as follows: propositions are really just properties of times, so that e.g. <there are dinosaurs $>$ is just the property $G$ such that for any time $t, G(t)$ just in case there are dinosaurs located at $t$. On this view, a permanent proposition is a proposition that is 'true-at' - i.e. possessed by - either every time or no times, and a temporary proposition is a proposition that is true-at some but not all times. In that case, the B-theory implies that there are temporary propositions - e.g. $<$ there are dinosaurs $>$ is true-at some but not all times - and therefore given the B-theory, Temporalism (in the form of Propositional Temporalism) is true. It follows that premise (2) of the argument from Priorian Change against the B-theory is false.

As mentioned in $\S 0$ above, if this argument is successful, it undercuts one of the primary motivations for Priorianism: to defend a 'dynamic' view of time in contrast to the 'static' B-theory. For if the B-theory implies Temporalism, then given Priorian Change, the B-theory is (from a Priorian perspective) just as much a theory according to which things 
really change as Priorianism is. So, how might Priorians respond to the above argument?

There are two ways for Priorians to resist the claim that the B-theory implies Temporalism. They rely on the important distinction drawn in $\S 1$ above between the two different ways in which Temporalism can be interpreted: either as involving irreducibly higher-order quantification into sentence position (i.e. as Sentential Temporalism), or as involving first-order 'objectual' quantification over propositions (i.e. as Propositional Temporalism). Let us consider each in turn.

First, suppose that Priorians identify Temporalism with Sentential Temporalism. The question then becomes: does the B-theory imply Sentential Temporalism? Now, the first point to note in answering this question is that B-theorists accept the reduction of the standard tense operators ('It was the case that', 'It will be the case that', etc.) to quantifiers over times. So, for example, according to the B-theory, a sentence of the form 'It was the case that $\varphi$ ' reduces to 'There is a time $t$ earlier than this time $u$ such that at $t, \varphi$ '; and a sentence of the form 'Sometimes, $\varphi$ ' reduces to 'There is a time $t$ such that at $t, \varphi$ '. Given that Sentential Temporalism is expressed above using the standard tense operator 'Sometimes', it follows that given the B-theory, Sentential Temporalism reduces to:

(4) There is a $p$ such that for some time $t$, at $t, p$, and for some time $t$, at $t$, not- $p$ $(\exists p(\exists t$ at $t(p) \wedge \exists t$ at $t(\neg p)))$

But (4) is false given the B-theory. In order to see this, we need to pay attention to another element of the B-theoretic reduction of the tense operators.

As we saw above, B-theorists analyse sentences of the form e.g. 'It was the case that $\varphi$ ' as 'There is a time $t$ earlier than this time $u$ such that at $t, \varphi$ '. But this is not the end of the story: for the sentence 'There is a time $t$ earlier than this time $u$ such that at $t, \varphi$ ' still contains 
a kind of tense operator, namely, the expression 'at (time) $t$ '. And in addition to providing an analysis of the standard tense operators, B-theorists also defend an analysis of 'at $t$ '. In particular, according to the B-theory, the function of 'at $t$ ' is to relativise predicates to times by binding unvoiced time-variables in the predicates in its scope. So, for example, according to the B-theory 'At $t$, there are dinosaurs' reduces to 'There are dinosaurs located at $t$ ', and 'At $t$, Jones is dancing' reduces to 'Jones bears the (permanent) dancing-at relation to $t$ ' (which may then be further analysed depending on which theory of persistence is accepted). ${ }^{20}$

Given the standard B-theoretic analysis of 'at $t$ ' just described, (4) is false according to the B-theory. The reason is that (4) is (by stipulation) a sentence of an irreducibly higherorder language, and as such, there are no predicates in the scope of the instances of 'at $t$ ' in (4): there is only the (irreducibly) higher-order variable ' $p$ '. Therefore, there are no predicates with unvoiced time-variables for the instances of 'at $t$ ' in (4) to bind, in which case the instances of 'at $t$ ' in (4) are redundant. But if the instances of 'at $t$ ' in (4) are redundant, then (4) is equivalent to the higher-order logical falsehood 'There is a $p$ such that $p$ and not-p' (' $\exists p(p \wedge \neg p ’))$. Therefore (4) - i.e. Sentential Temporalism - is false according to the Btheory. Moreover, it follows that the sentence

(5) There is no $p$ such that sometimes $p$ and sometimes not- $p$ $(\neg \exists p(\mathrm{~S} p \wedge \mathrm{S} \neg p))$

is (logically) true according to the B-theory. But (5) is equivalent to Sentential Atemporalism, i.e. Atemporalism read as involving irreducibly higher-order quantification. In short, if Temporalism is identified with Sentential Temporalism, then the B-theory implies Sentential

\footnotetext{
${ }^{20}$ For example, according to some B-theorists, for someone to bear the dancing-at relation to a time $t$ is for them to have an 'instantaneous temporal part' located at $t$ that is dancing (simpliciter). See e.g. Sider (2001).
} 


\title{
Atemporalism.
}

We have looked at one way for Priorians to resist the claim that the B-theory implies Temporalism: that is, to interpret Temporalism as equivalent to Sentential Temporalism, i.e. as involving irreducibly higher-order quantification. Priorians may argue that the relative simplicity of this strategy speaks in its favour. Moreover, as mentioned above in $§ 1$, Prior himself was a significant defender of the intelligibility of irreducibly higher-order quantification. ${ }^{21}$ For example, here is Prior $(1971,36)$ :

\begin{abstract}
All this can be carried over, mutatis mutandis, into the discussion of quantifications over variables of other categories, and there isn't the least need to equate them with name variables in order to see what is going on. 'For some $\varphi$, Peter $\varphi$ 's' is true if any specification of it is true, meaning by a 'specification' of it any statement in which the indefinite verb 'does something' or 'acts somehow' is replaced by some specific verb or equivalent expression, e.g. 'is red-haired'; and it is of course true if and only if, for some $\varphi$, Peter $\varphi$ 's. It hasn't any quite exact colloquial expression in English, because such variable verbs as 'do' tend to stand only for verbs of a particular sort - 'Peter is red-haired' would not be thought of as a natural specification of 'Peter does something'. 'Peter is or does something' would perhaps catch the full generality of 'For some $\varphi$, Peter $\varphi$ 's' well enough, and the way it works is clear.... In all this I cannot see anything mysterious, or anything that need compel us to treat variables that do not stand for names of objects as if they did.
\end{abstract}

However, some B-theorists may question the intelligibility of irreducibly higher-order languages. As mentioned above in $\S 1$, natural languages such as English do not seem to provide us with the relevant conceptual resources: natural language quantification is almost invariably objectual (i.e. involves quantification over things). So how can we ever come to understand irreducibly higher-order languages? According to Williamson $(2013,459)$, such

\footnotetext{
${ }^{21}$ See also Bostock (2004); Dorr (2016, §4); Frege (1879); Jones (2018; 2019); Rayo \& Yablo (2001); and Williamson (2003).
} 
languages must be learnt 'by the direct method':

Perhaps no reading in a natural language of quantification into predicate position is wholly satisfactory. If so, that does not show that something is wrong with quantification into predicate position, for it may reflect an expressive inadequacy in natural languages. We may have to learn second-order languages by the direct method, not by translating them into a language with which we are already familiar. At some point, we learn to understand [certain] symbols directly; why not use the same method for $\forall F$ ? We must learn to use higher-order languages as our home language.

B-theorists may also object that the argument that the B-theory implies the falsehood of Temporalism because it implies the falsehood of Sentential Temporalism in some sense confuses logic with metaphysics; that it involves 'pulling a metaphysical rabbit out of a logical hat'. Priorian friends of irreducibly higher-order quantification can respond to this objection by arguing that insofar as we treat irreducibly higher-order quantification as primitive and accept the Lewisian view that the unanalysed expressions in which we couch our theories in some sense reflect the fundamental structure of reality 22 - i.e. 'carve reality at its joints' - a commitment to irreducibly higher-order quantification reflects not just a commitment to a certain choice of logic, but to a certain theory of fundamental reality (i.e. as having fundamental higher-order structure).

Finally, B-theorists may object that the argument that the B-theory implies the falsehood of Temporalism because it implies the falsehood of Sentential Temporalism 'loads the dice' against the B-theory by shifting the debate to less favourable ground for B-theorists. After all, as we saw at the top of this section, the most natural B-theoretic interpretation of Temporalism on which that thesis is true given the B-theory is one according to which Temporalism is equivalent to Propositional Temporalism. Let us therefore consider another

\footnotetext{
${ }^{22}$ See especially Lewis (1983) and Sider (2011). Note that both Lewis and Sider are B-theorists.
} 
way for Priorians to resist the claim that the B-theory implies Temporalism. This strategy involves agreeing with B-theorists that Temporalism ought to be identified with Propositional Temporalism, but then arguing that Propositional Temporalism ought to be interpreted as involving a monadic, rather than a dyadic, truth property.

To see how this strategy works, we need to carefully unpack the B-theorist's proposed interpretation of Temporalism described above. In arguing that their view implies Temporalism, B-theorists begin by identifying Temporalism with Propositional Temporalism. They then apply the standard B-theoretic analysis of 'Sometimes, $\varphi$ ' (as 'There is a time $t$ such that at $\left.t, \varphi^{\prime}\right)$ to Propositional Temporalism to get:

(6) For some $x, x$ is a proposition and at some time $t, x$ is true, and at some time $t, x$ is false $(\exists x(\operatorname{Proposition}(x) \wedge \exists t$ at $t(\operatorname{True}(x)) \wedge \exists t$ at $t(\neg \operatorname{True}(x))))$

Next, the standard B-theoretic analysis of the tense operator 'at (time) $t$ ' - on which the function of 'at $t$ ' is to bind unvoiced time-variables in the predicates in its scope - is applied to (6), to get:

(7) For some $x, x$ is a proposition and there is a time $t$ such that $x$ is true-at $t$, and a time $t$ such that $x$ is not true-at $t$ $(\exists x(\operatorname{Proposition}(x) \wedge \exists t \operatorname{True}(x, t) \wedge \exists t \neg \operatorname{True}(x, t)))$

Propositions are then identified with properties of times, and the two-place true-at relation between propositions and times in (7) is analysed in terms of the (permanent) instantiation relation, so that for a proposition $p$ to be true-at a time $t$ is just for $p$ to be instantiated by $t$. 
Thus, we see that in order to provide an interpretation of Propositional Temporalism on which it is true according to the B-theory, B-theorists must interpret the truth-predicate in the statement of Propositional Temporalism as expressing a dyadic property - i.e. the (permanent) true-at relation between propositions and times. It follows that Priorians can resist the conclusion that the B-theory implies Propositional Temporalism by arguing that the truth predicate in the statement of Propositional Temporalism ought to be interpreted as expressing the (temporary) monadic property of truth simpliciter. For if the instances of the predicate 'is true' in (6) express a monadic property then they do not contain unvoiced timevariables, in which case there is nothing for the instances of 'at $t$ ' in (6) to operate on. But if there is nothing for the instances of 'at $t$ ' in (6) to operate on, they are redundant. It follows that given the B-theory, (6) is equivalent to the (first-order) logical falsehood 'There is an $x$ such that $x$ is a proposition and $x$ is both true and false' (' $\exists x(\operatorname{Proposition}(x) \wedge \operatorname{True}(x) \wedge$ $\left.\neg \operatorname{True}(x))^{\prime}\right)$. Therefore (6) - i.e. Propositional Temporalism - is false according to the Btheory. Moreover, it follows that the sentence

(8) There is no $x$ such that $x$ is a proposition, and sometimes $x$ is true, and sometimes $x$ is false $(\neg \exists x(\operatorname{Proposition}(x) \wedge \mathrm{S} \operatorname{True}(x) \wedge \mathrm{S} \neg \operatorname{True}(x)))$

is (logically) true according to the B-theory. But (8) is equivalent to Propositional Atemporalism, i.e. Atemporalism read as involving first-order quantification over propositions. In short, if Temporalism is identified with the view that some propositions change in truth-value simpliciter over time, then the B-theory implies Propositional Atemporalism.

We have looked at a second way for Priorians to resist the claim that the B-theory 
implies Temporalism; one which does not rely on an appeal to irreducibly higher-order languages, and which agrees with B-theorists that Temporalism ought to be identified with Propositional Temporalism. B-theorists may respond to this strategy by arguing that to interpret the truth-predicate in Propositional Temporalism as expressing the property of truth simpliciter simply 'begs the question' against their view: of course (they may say) the Btheory implies the falsehood of Propositional Temporalism when that thesis is interpreted as involving monadic truth rather than the true-at relation between propositions and times.

However, Priorians can respond that the charge of 'begging the question' carries limited force in this case. In particular, Priorians can argue that the idea that propositions are true or false simpliciter - and not merely relatively true or false - has strong intuitive force irrespective of one's views on the metaphysics of time. ${ }^{23}$ Some B-theorists who accept that Temporalism (in the form of Propositional Temporalism) is a necessary condition for there being change over time may feel the pull of monadic truth. And even those who do not feel that pull may yet acknowledge that the arguments for and against monadic truth are at least less question-begging than e.g. the Priorian arguments for rejecting the B-theoretic account of change as 'variation along the temporal dimension'. ${ }^{24}$

B-theorists may respond here that a commitment to the view that there are 'temporary propositions' in the sense of propositions that are true-at some but not all times does not preclude a commitment to there being a monadic property of propositions of truth simpliciter. For example, they can argue that there is a difference between propositions as the contents of the propositional attitudes such as belief and desire, which are often 'temporary' in the sense of being true-at some but not all times, and propositions as the primary bearers of truth

\footnotetext{
${ }^{23}$ Note that a commitment to the view that propositions are true/false simpliciter does not preclude holding that some propositions are also true/false relative to times. For example, Priorians who identify times with maximal, consistent, sometimes-true propositions will naturally hold that for any $p, p$ is true-at a time $t$ just in case $t$ implies $p$. It follows that for any $p, p$ is true simpliciter just in case $p$ is true-at the present (i.e. true) time. The key point here is that for such Priorians, truth-at is analysed in terms of truth simpliciter.

${ }^{24}$ See especially Cappelen \& Hawthorne (2009) for arguments concerning monadic truth.
} 
values, which are if true always true (simpliciter). Something like this strategy is defended by e.g. Sider $(2001,20-21)$, who refers to propositions of the first kind as 'temporal propositions'. This strategy incurs some obvious costs, however: first, of splitting the 'proposition' role between propositions of the first sort and propositions of the second; and second, of implying that the way that we represent reality in thought (as temporal) is not the way that reality actually is (i.e. atemporal).

B-theorists may also object that by insisting on interpreting the truth predicate in Propositional Temporalism as expressing the temporary monadic property of truth simpliciter, Priorians are simply baking their own notion of change into Temporalism, and therefore (again) 'begging the question' against the B-theory (according to which change consists in variation along the temporal dimension). This would be particularly problematic, since premise (1) of the Priorian argument against the B-theory is Priorian Change, which states that Temporalism is a necessary condition for there being change over time.

As above, however, Priorians should respond to this objection by pointing out that the idea that propositions change in truth value simpliciter has intuitive force independent of one's views on the metaphysics of time, and in particular on the nature of change. A natural way for Priorians to defend this claim is by analogy. Suppose that according to the B-theory, $<$ Jones is dancing at $u>$ (where $u$ names this time) is (permanently) true simpliciter. Most Btheorists will also accept that that proposition is contingently true: Jones could have failed to dance at $u$. In other words, most B-theorists will accept that $<$ Jones is dancing at $u>$ is true simpliciter but could have been false simpliciter; and more generally, that contingency involves possible variation in properties simpliciter (rather than variation in properties relative to worlds, or variation in properties simpliciter between otherworldly counterparts see e.g. Lewis 1968). Priorians can argue that this natural view of contingency also applies to the temporal case. 
We have seen that Priorians can defend their claim that the B-theory is true only if Temporalism is false (which is a key premise of their argument from Priorian Change against the B-theory) either by identifying Temporalism with Sentential Temporalism or by identifying Temporalism with Propositional Temporalism and arguing that the truth predicate in the statement of Propositional Temporalism ought to be interpreted as expressing a monadic property. We have also seen that neither strategy is likely to convince a committed B-theorist that their view is one according to which nothing ever changes. In particular, I do not claim that Priorians can entirely avoid the accusation of in some sense 'begging the question' against the B-theory in marshalling the argument from Priorian Change. But my aim in this section has not been to describe a version of the argument from Priorian Change against the B-theory that cannot be charged with 'begging the question'. Rather, as mentioned in $\S 0$ above, my aim has been to describe what I take to be the best available Priorian response to the argument that the B-theory implies Temporalism.

\section{Cameronian Change}

In the previous section I defended Priorianism by defending the argument from Priorian Change against the B-theory. In this section I defend Priorianism by defending Priorian Change. I do so indirectly, by arguing against an alternative necessary condition for there being change over time due to Cameron (2015). As we shall see, Cameron does not state his alternative to Priorian Change explicitly: rather, his commitment to the principle emerges in the course of his defence of (a version of) the Moving Spotlight Theory (MST). Therefore, it is necessary to describe Cameron's version of MST, and what he takes to be its main rival, before we can properly consider his alternative to Priorian Change.

Cameron (2015) defends a non-standard version of MST that combines three core theses: first, that the past and future are concrete parts of reality; second, that every individual 
possesses a temporary fundamental age property (where for all $x, x$ 's age is the amount of time that has passed since $x$ began to occupy spacetime); and third, that every individual possesses a permanent fundamental temporal distribution property (i.e. a fundamental property of having a certain cross-time qualitative profile). As Cameron's theory is essentially a version of MST where the temporary fundamental 'spotlight' of presentness is replaced with the temporary fundamental 'ages' of occupants of spacetime, let us call Cameron's view the Moving Ages Theory (MAT).

Cameron argues that it is an advantage of MAT that, unlike standard versions of MST, it 'avoids having to take any tensed fact as fundamental' (ibid, 127), and therefore implies the truth of Anti-tensism:

Anti-tensism: There are no fundamental tense-logical operators (i.e. sentence operators such as 'It was the case that' ('P'), 'It will be the case that' ('F'), and 'It is the case at time $t$ that' ('At (time) $t^{\prime}$ ))

However, Cameron's acceptance of Anti-tensism is not based on an acceptance of reductive analyses of the standard tense operators. ${ }^{25}$ Rather, according to Cameron, the goal of theories of time should be to provide 'tenseless' - i.e. tense operator-free - truthmakers for true 'tensed' propositions, where a proposition $p$ is a truthmaker for a proposition $q$ just in case ' $p$ 's being the case explains, in more fundamental terms, why $q$ is the case' (Cameron ibid, 114). We can get a feel for Cameron's 'tenseless truthmakers for tensed truths' via some examples. For instance, on Cameron's view, <there used to be dinosaurs $>$ is made true by the truth of $<$ the state of affairs of there being dinosaurs located at a time earlier than the present time exists $>$; and $<$ I will be entirely grey-haired $>$ is made true by the truth of $<$ the state of

\footnotetext{
${ }^{25}$ Or, indeed, on the rejection of 'standard realism' á la Fine's (2005) fragmentalism. See especially Lipman (2015) for a careful discussion of Fine's view.
} 
affairs of my having a certain age, temporal distributional property, and spatiotemporal location exists>.

As Cameron (ibid, 77ff) points out, however, he faces a problem: the arguments he uses to motivate MAT also motivate an apparently simpler version of MST inspired by Bricker's (2006) theory of modality. Let us call this view Bricker's Spotlight Theory (BST). BST differs from MAT in two important respects. First, whereas according to MAT there are many temporary fundamental properties - i.e. the temporary fundamental ages of occupants of spacetime - according to BST, there is exactly one temporary fundamental property: the temporary fundamental property of presentness possessed by this time. ${ }^{26}$ Second, whereas according to MAT propositions concerning change in which time is present (such as $<1966$ was but is no longer present>) are ultimately grounded in the existence of states of affairs of things having certain ages, according to BST, such propositions reduce to propositions concerning temporal relations between times and a present time, as follows:

For any time $t, t$ was present just in case $t$ is earlier than a present time $\left(\forall t\left(\mathrm{P}(\operatorname{Presen} t(t)) \leftrightarrow \exists t^{*} \operatorname{Present}\left(t^{*}\right) \wedge t<t^{*}\right)\right)$

For any time $t, t$ will be present just in case $t$ is later than a present time $\left(\forall t\left(\mathrm{~F}(\operatorname{Presen} t(t)) \leftrightarrow \exists t^{*} \operatorname{Presen} t\left(t^{*}\right) \wedge t^{*}<t\right)\right)$

For example, according to BST, $<1966$ was present $>$ reduces to $<1966$ is earlier than a present time $>$, and $<2066$ will be present $>$ reduces to $<2066$ is later than a present time $>{ }^{27}$

\footnotetext{
${ }^{26}$ The question of whether the fundamental property of presentness really is temporary given BST is one that I return to below.

${ }^{27}$ BST is not merely a straw-man alternative to Cameron's view: a very similar view is defended by Deasy (2015). I discuss Deasy's view in more detail below.
} 
Like MAT, BST implies Temporal Disparity and Anti-tensism. ${ }^{28,29}$ In that sense, the view shares many of the virtues that Cameron claims for MAT. However, Cameron (ibid, 85) argues that we should prefer MAT to BST on the grounds that unlike MAT, BST implies that nothing ever changes.

Cameron's argument for this conclusion is as follows: ${ }^{30}$ there is a theory - call it the Frozen Spotlight Theory (FST) - which implies exactly the same complete fundamental description of reality as BST, but according to which it is always the case that this time $u$ is present. (For example, suppose that according to FST, the operator 'Always' in the sentence 'Always, $u$ is present' is redundant, so that $<u$ is present $>$ is equivalent to $<$ always, $u$ is present>.) In other words, FST agrees with BST on all of the fundamental facts, but also implies that presentness is 'frozen' at this time. But if FST implies that presentness is 'frozen' at this time then given that (by definition) every property other than presentness is permanent according to FST, FST implies that every property is permanent. It follows that FST implies Propositional Atemporalism. ${ }^{31}$ And according to Cameron, in that case we can argue against BST as follows:

(1) For any theory $T$, if there is a theory $T^{*}$ such that (i) the fundamental description of the world $D$ according to $T=$ the fundamental description of the world $D^{*}$ according to $T^{*}$ and (ii) $T^{*}$ implies Propositional Atemporalism, then $T$ implies that nothing ever changes

\footnotetext{
${ }^{28}$ According to Cameron (in correspondence), given MAT, this time $u$ time is present in virtue of being the unique time $t$ such that for all $x, x$ 's age at $t$ is $x$ 's age simpliciter. I assume this metaphysically distinguishes $u$ from all other times, so that MAT implies Temporal Disparity.

${ }^{29}$ The idea is that given BST, the only role for the tense operators is to capture change in which time is present; therefore, given the above analyses, there are no fundamental tense operators given BST.

${ }^{30}$ This is my own reconstruction of Cameron's argument.

${ }^{31}$ Where the truth-predicate is interpreted as expressing a monadic property.
} 
(2) There is a theory $T^{*}$ - namely, FST - such that (i) the fundamental description of the world $D$ according to BST $=$ the fundamental description of the world $D^{*}$ according to $T^{*}$ and (ii) $T^{*}$ implies Propositional Atemporalism

Therefore

(c) BST implies that nothing ever changes

This is Cameron's argument for preferring MAT to BST. Notice that premise (1) expresses a necessary condition for a theory's being one according to which there is change over time - it is equivalent to:

Cameronian Change: For any theory $T, T$ implies that there is change over time only if there is no theory $T^{*}$ such that (i) the fundamental description of the world $D$ according to $T=$ the fundamental description of the world $D^{*}$ according to $T^{*}$ and (ii) $T^{*}$ implies Propositional Atemporalism

This is Cameron's alternative to Priorian Change. Cameronian Change is importantly different to Priorian Change: in particular, a theory can satisfy Priorian Change without satisfying Cameronian Change. For example, imagine a theory $T$ on which Propositional Temporalism is true, but not fundamentally true; for example, because the tense operators (including 'at $t$ ') have some reductive analysis - a 'fancy semantics' as Cameron (ibid, 167) memorably puts it. $T$ satisfies Priorian Change, but it may not satisfy Cameronian Change: there may be a theory $T^{*}$ which agrees with $T$ as regards the fundamental facts but provides an alternative analysis of the tense operators given which Propositional Atemporalism is 
(non-fundamentally) true. In effect, Cameronian Change adds the following additional necessary condition for change to Priorian Change: that Temporalism (in the form of Propositional Temporalism) is true given the fundamental facts. According to Cameron, MAT satisfies this extra condition, but BST does not.

But does MAT really satisfy that extra condition? Consider a theory - call it the Eternal Ages Theory (EAT) - which implies exactly the same complete fundamental description of reality as MAT, but according to which everything always has the age it has now. (For example, suppose that according to EAT, the operator 'Always' in the sentence 'Always, Queen Anne is 354 years old' is redundant, so that <Queen Anne is 354 years old $>$ is equivalent to <always, Queen Anne is 354 years old $>$.) In other words, EAT agrees with MAT on all of the fundamental facts, but also implies that the ages of things are 'frozen'. But if EAT implies that the ages of things are 'frozen', then given that (by definition) all properties other than age-properties are permanent according to EAT, EAT implies that every property is permanent. It follows that EAT implies Propositional Atemporalism. And in that case, we can argue against MAT as follows:

(3) For any theory $T$, if there is a theory $T^{*}$ such that (i) the fundamental description of the world $D$ according to $T=$ the fundamental description of the world $D^{*}$ according to $T^{*}$ and (ii) $T^{*}$ implies Propositional Atemporalism, then $T$ implies that nothing ever changes

(4) There is a theory $T^{*}$ - namely, EAT - such that (i) the fundamental description of the world $D$ according to MAT $=$ the fundamental description of the world $D^{*}$ according to $T^{*}$ and (ii) $T^{*}$ implies Propositional Atemporalism 
Therefore

(c) MAT implies that nothing ever changes

In other words, it seems that there is an argument exactly analogous to Cameron's argument against BST against his own view.

How should Cameron respond to this argument? There are two options: either reject premise (3) - in other words, reject Cameronian Change - or accept Cameronian Change and instead reject premise (4). In what follows I consider both of these options, in reverse order. I conclude that the best way for Cameron to respond to the above argument is to reject Cameronian Change in favour of Priorian Change.

One way for Cameron to respond to the above argument is to reject premise (4), on the grounds that there is no such Propositional Atemporalist theory as EAT. In particular, Cameron could argue that for any theory $T$, if the complete fundamental description of the world $D$ according to $T=$ the complete fundamental description of the world $D^{*}$ according to MAT, then $T$ implies Propositional Temporalism. But why believe that? The idea is that it is 'of the (metaphysical) essence of' fundamental age properties - i.e. fundamental properties of the form being $n$ units of time old - that they are temporary. For example, here is Cameron (ibid, 168; my emphases): ${ }^{32}$

\footnotetext{
In saying that things were a certain way, my moving spotlighter is saying something about the very nature of things. It is of the essence of things that have such-and-such a temporal distributional property and so-and-so an age that they are a certain way now, but it is also of the essence of things that have those properties that they were and will be some other way.
}

${ }^{32}$ See also Cameron (2017). 
But what exactly does it mean to say that it is of the essence of fundamental age properties that they are temporary? According to Cameron, this means that necessarily, if it is a fundamental truth that some $x$ is $n$ units of time old, then the existence of the state of affairs of $x$ 's being $n$ units of time old, together with the essence of the property being $n$ units of time old, makes it true that $x$ was $n-1$ units of time old ${ }^{33}$ It follows that for any theory $T$, if the fundamental description of the world $D$ according to $T$ implies that things possess fundamental age properties, $T$ implies Propositional Temporalism; and therefore there is no such theory as EAT according to which things possess fundamental age properties and Propositional Atemporalism is true. In short, given the kinds of properties that ages are, theories such as MAT that posit fundamental ages cannot fail to satisfy Cameronian Change. However, there is a problem with this response for Cameron. The problem is that Cameron's rejection of premise (4) is inconsistent with his (ibid, 127) claim that MAT 'avoids having to take any tensed fact as fundamental'. To see this, remember that according to Cameron, to hold that fundamental age properties are 'essentially temporary' is to commit to the following claim - call it Essential Temporality:

Essential Temporality: If it is a fundamental truth that some $x$ is $n$ units of time old, then the existence of the state of affairs of $x$ 's being $n$ units of time old, together with the essence of the property being $n$ units of time old, makes it true that $x$ was $n-1$ units of time old

Now we can ask: given MAT, is Essential Temporality itself a fundamental truth? Cameron may respond that it is not, because it is made true by its instances. But in that case, take any instance of Essential Temporality - for example, $<$ the existence of the state of affairs of my

\footnotetext{
${ }^{33}$ Cameron (in correspondence).
} 
being $n$ years old together with the essence of the property being $n$ years old makes it true that I was $n-1$ years old $>$. Call that proposition $P$. We can then ask whether $P$ is a fundamental truth given MAT. It seems Cameron must answer that it is: it is hard to see what could be said about what makes $P$ true. But notice that $P$ involves the tense operator 'It was the case that' ('I was $n-1$ years old'). In that case, it follows that given MAT, there are fundamental 'tensed' truths, and therefore it is not the case that MAT 'avoids having to take any tensed fact as fundamental'. But that would be a serious problem for Cameron, as he takes it to be one of the significant virtues of MAT that it implies Anti-tensism.

I have described one potential response on Cameron's behalf to the argument that MAT implies that nothing ever changes, namely, to reject premise (4) of that argument. However, we have seen that that strategy is inconsistent with Cameron's rejection of fundamental tense. I suggest that a better way for Cameron to respond to the argument is to reject premise (3) - i.e. Cameronian Change - in favour of the view that for any theory $T, T$ implies that there is change over time only if $T$ implies Propositional Temporalism - i.e. in favour of Priorian Change. In that case, Cameron can allow that there is a Propositional Atemporalist theory $T$ - namely, EAT - such that the fundamental description of the world $D$ according to MAT $=$ the fundamental description of the world $D^{*}$ according to $T$, but deny that it follows that given MAT, nothing ever changes. Rather, Cameron can argue that given that MAT implies the (non-fundamental) truth of Propositional Temporalism, there is no obvious threat to the claim that his view is one according to which there is change over time.

But does MAT secure the truth of Propositional Temporalism? According to Cameron (in correspondence), given MAT, Propositional Temporalism is made true by any of its instances. For example, let ' $P$ ' name the truth that sometimes I am sitting and sometimes I am not sitting. According to Cameron, the truth that for some proposition $p$, sometimes $p$ is true and sometimes $p$ is not true (i.e. Propositional Temporalism) is made true by the existence of 
the state of affairs of $P$ 's being true; and $P$ in turn is made true by my having a certain temporary age and permanent temporal distributional property.

Of course, there is a cost to this response for Cameron: as we saw above, Cameronian Change is a premise in Cameron's argument against BST, which he takes to be a rival to his own view. The question, then, is whether Cameron use Priorian Change to argue against BST.

In order to address this question, let us consider Deasy's (2015) version of MST. Like BST, Deasy's MST combines Temporal Disparity (in the form of the view that presentness is the one and only temporary fundamental property) with Anti-tensism. Moreover, like BST, Deasy's MST implies that the only role for the tense operators is in describing change in which time possesses fundamental presentness. However, according to Deasy (ibid, 2078-9), MSTers should also accept that 'ordinary' predicates express temporary properties of bearing certain permanent relations to a present time, so that e.g. the predicate 'is sitting' expresses the temporary (monadic) property of sitting-at a present time. ${ }^{34}$ Let us call this view About Presentness:

About Presentness: For each property $F$ expressed by an ordinary predicate, there is a permanent relation $R$ such that $F$ is the temporary property of bearing $R$ to a present time

In addition to About Presentness, Deasy (ibid, 2080) accepts the standard 'quantificational' analyses of the tense operators ' $\mathrm{P}$ ' and ' $\mathrm{F}$ ' in terms of quantification over times and 'at (time) $t^{\prime}:$

\footnotetext{
${ }^{34}$ Sider $(2017,790$, n.2) also recommends this view to MSTers.
} 
It was the case that $\varphi$ just in case there is a time earlier than a present time at which it is the case that $\varphi$

$\left(\mathrm{P} \varphi \leftrightarrow \exists t \exists t_{1}\left(\operatorname{Present}(t) \wedge t_{1}<t \wedge\right.\right.$ at $\left.\left.t_{1}(\varphi)\right)\right)$

It will be the case that $\varphi$ just in case there is a time later than a present time at which it is the case that $\varphi$

$\left(\mathrm{F} \varphi \leftrightarrow \exists t \exists t_{1}\left(\operatorname{Present}(t) \wedge t<t_{1} \wedge\right.\right.$ at $\left.\left.t_{1}(\varphi)\right)\right)$

Finally, Deasy (ibid, 2081-2) defends the following 'substitutional analysis' of the tense operator 'at $t$ ':

The Substitutional Analysis: For it to be the case that at $t(\varphi)$ (where $\varphi$ is a sentence free from tense operators and 'at $t$ ', and in which the only formulae that attribute temporary properties are formulae of the form ' $x$ is present') is for it to be the case that $\varphi[=t / \text { present }]^{35}$

To see how Deasy's analysis works in practice, consider the sentence ' $\mathrm{P}(\exists x \operatorname{Dodo}(x))$ ' ('It was the case that something is a dodo'). Given About Presentness and the quantificational analysis of ' $\mathrm{P}$ ', this sentence reduces to:

(5) There is a time earlier than a present time at which something is a dodo-at a present time

\footnotetext{
${ }^{35}$ Although Deasy refers to this as an 'analysis' of 'at $t$ ', it looks more like a way of systematically translating sentences involving 'at $t$ ' into sentences of the tense operator-free fundamental language of MST. However, not much of importance rests on this point, so I will continue to refer to it as an 'analysis'.
} 
$\left(\exists t \exists t_{1}\left(\operatorname{Present}(t) \wedge t_{1}<t \wedge\right.\right.$ at $\left.\left.t_{1}\left(\exists x \exists t_{2} D\left(x, t_{2}\right) \wedge \operatorname{Present}\left(t_{2}\right)\right)\right)\right)$

Given the Substitutional Analysis, (5) reduces to:

(6) There is a time $t$ earlier than a present time such that something is a dodo-at $t$ $\left(\exists t \exists t_{1}\left(\operatorname{Present}(t) \wedge t_{1}<t \wedge \exists t_{2} t_{1}=t_{2} \wedge \exists x D\left(x, t_{2}\right)\right)\right)$

Similarly, consider the sentence:

(7) Sometimes, something is sometimes present and sometimes not present $(\mathrm{S} \exists x(\operatorname{SPresent}(x) \wedge \mathrm{S} \neg \operatorname{Present}(x)))$

Given the quantificational analyses of ' $\mathrm{P}$ ' and ' $\mathrm{F}$ ' and the standard definition of ' $\mathrm{S}$ ' in terms of 'P' and 'F' ( $\left.\mathrm{S} \varphi={ }_{\text {def }} \mathrm{P} \varphi \vee \varphi \vee \mathrm{F} \varphi\right)$, (7) reduces to:

(8) At some time $t$, something is such that there is a time at which it is present and a time at which it is not present $\left(\exists t\left(\right.\right.$ at $t\left(\exists x \exists t_{1}\right.$ at $t_{1}(\operatorname{Present}(x)) \wedge \exists t_{2}$ at $\left.\left.\left.t(\neg \operatorname{Present}(x))\right)\right)\right)$

Given the Substitutional Analysis, (8) reduces to:

(9) There are at least two times

$\left(\exists x\left(\exists t x=t \wedge \exists t^{*} \neg x=t^{*}\right)\right)$

In short, given Deasy's Substitutional Analysis, presentness is temporary just in case there 
are at least two times, which is of course true given MST. It follows that the combination of the Substitutional Analysis with MST secures the temporariness of presentness - at least, in the sense of securing the truth of (7). But does it secure the truth of Temporalism?

First, consider Sentential Temporalism. Given the quantificational analyses of 'P' and ' $\mathrm{F}$ ' and the standard definition of ' $\mathrm{S}$ ' in terms of ' $\mathrm{P}$ ' and ' $\mathrm{F}$ ', Sentential Temporalism reduces to:

(10) There is a $p$ such that for some time $t$, at $t, p$ and for some time $t$, at $t$, not- $p$ $(\exists p(\exists t$ at $t(p) \wedge \exists t$ at $t(\neg p)))$

But given that there are no instances of the predicate 'is present' in the scope of the instances of 'at $t$ ' in (10) (there is only the irreducibly higher-order variable ' $p$ '), given the Substitutional Analysis the instances of 'at $t$ ' in (10) are redundant. But if the instances of 'at $t$ ' in (10) are redundant then (10) is equivalent to the higher-order logical falsehood 'There is a $p$ such that $p$ and not- $p$ ' (' $\exists p(p \wedge \neg p ’))$. Therefore (10) - i.e. Sentential Temporalism - is false given Deasy's MST.

What about Propositional Temporalism? Given the quantificational analyses of 'P' and ' $\mathrm{F}$ ' and the standard definition of ' $\mathrm{S}$ ' in terms of ' $\mathrm{P}$ ' and ' $\mathrm{F}$ ', Propositional Temporalism reduces to:

(11) For some $x, x$ is a proposition and at some time $t, x$ is true, and at some time $t, x$ is false $(\exists x(\operatorname{Proposition}(x) \wedge \exists t$ at $t(\operatorname{True}(x)) \wedge \exists t$ at $t(\neg \operatorname{True}(x))))$

Now the question for Deasy is whether the predicate 'is true' in (11) counts as an 'ordinary 
predicate'. If not, then given the Substitutional Analysis, the instances of 'at $t$ ' in (11) are again redundant, and (11) is equivalent to the logical falsehood that some proposition is both true and false, in which case Deasy's MST implies the falsehood of Propositional Temporalism. On the other hand, if the predicate 'is true' in (11) counts as an 'ordinary predicate' then given About Presentness and the Substitutional Analysis, (11) is equivalent to:

(12) For some $x, x$ is a proposition and there is a time $t$ such that $x$ is true-at $t$, and a time $t$ such that $x$ is not true-at $t$ $(\exists x(\operatorname{Proposition}(x) \wedge \exists t \operatorname{True}(x, t) \wedge \exists t \neg \operatorname{True}(x, t)))$

But notice that (12) is exactly the B-theoretic interpretation of Propositional Temporalism described in $\S 2$ above, according to which a proposition is 'temporary' just in case it bears the permanent true-at relation to some but not all times. Therefore, given the Priorian view defended there that Propositional Temporalism must be interpreted as involving monadic truth, Deasy's MST counts as a view on which Propositional Temporalism is false, and hence (given Priorian Change) as a view on which nothing ever changes. It follows that if Deasy's view is representative of BST, given an acceptance of Priorian Change, Cameron is in a position to argue that BST is (unlike MAT) a 'frozen spotlight theory'.

\section{Conclusion}

To summarise: it is difficult to provide arguments in favour of Priorianism that do not incur the charge of 'begging the question' against those who reject the view. However, that does not mean that it is not possible to defend the view. In this paper, I have attempted to defend Priorianism by doing three things: first, by making clear exactly what the view is $(\S 1)$; 
second, by showing how Priorians can respond to the argument that the B-theory is just as 'dynamic' as Priorianism (§2); and finally, by arguing that Cameron (2015) has good reasons to accept Priorian Change - and therefore to accept Priorianism - rather than his own alternative principle of change, which I called (for want of a better name) 'Cameronian Change' $(\S 3) .{ }^{36}$

\section{References}

Barlassina, L. \& F. Del Prete (2015). The Puzzle of the Changing Past. Analysis 75: 59-67

Bostock, D. (2004). On Motivating Higher-Order Logic. In Smiley, T. J. \& T. Baldwin (eds.) Studies in the Philosophy of Logic and Knowledge. Oxford University Press

Brogaard, B. (2012). Transient Truths. Oxford University Press

Cameron, R. (2015). The Moving Spotlight: An Essay on Time and Ontology. Oxford University Press (2017). Reply to Miller, Sider and Skow. Analysis 77: 810-24

Cappelen, H. \& J. Hawthorne (2009). Relativism and Monadic Truth. Oxford University Press

Deasy, D. (2015). The Moving Spotlight Theory. Philosophical Studies 172: 2073-89

Deng, N. (2013). Fine's McTaggart, Temporal Passage, and the A versus B-Debate. Ratio 26: $19-34$

Fine, K. (2005). Tense and Reality. In K. Fine. Modality and Tense: Philosophical Papers. Oxford University Press

Forbes, G. (2016). The Growing Block's Past Problems. Philosophical Studies 173: 699-709

Forrest, P. (2004). The Real But Dead Past: Reply to Braddon-Mitchell. Analysis 64: 358-362

\footnotetext{
${ }^{36}$ I am grateful to an audience from Trinity College, Dublin and the Society for the Philosophy of Time (SPoT) for comments on an earlier version of this paper. I am especially grateful to Luca Banfi and an anonymous referee for this journal for comments on the MS. This paper is dedicated to my father William P. Deasy (19462019). Thanks for everything Bill.
} 
Frege, G. (1879). Begriffsschrift, eine der arithmetischen nachgebildete Formelsprache des reinen Denkens, Louis Nebert; translated as Concept Script, a formal language of pure thought modelled upon that of arithmetic, by S. Bauer-Mengelberg in J. van Heijenoort (ed.) (1967) From Frege to Gödel: A Source Book in Mathematical Logic, 1879-1931. Harvard University Press

Jones, N. K. (2018). Nominalist Realism. Nô̂s. DOI: 10.1111/nous.12193 . (2019). Propositions and Cognitive Relations. Proceedings of the Aristotelian Society 119: $157-178$

Leininger, L. (2015). Presentism and the Myth of Passage. Australasian Journal of Philosophy 93: 724-739

Lewis, D. (1968). Counterpart Theory and Quantified Modal Logic. The Journal of Philosophy 65: 113-126 . (1983). New Work for a Theory of Universals. Australasian Journal of Philosophy 61: 343-377.

Lipman, M. (2013). A Passage Theory of Time. In K. Bennett and D. W. Zimmerman (eds.) Oxford Studies in Metaphysics, Vol. 11. Oxford University Press. 95-122 . (2015). On Fine's fragmentalism. Philosophical Studies 172: 3119-3133

Marcus, R. B. (1961). Modalities: Philosophical Essays. Oxford University Press

Markosian, N. (2004). In Defence of Presentism. In D. Zimmerman (ed.). Oxford Studies in Metaphysics Volume 1. Oxford University Press

Mellor, D. H. (1998). Real Time II. Routledge

Prior, A. (1968). Papers on Time and Tense. Oxford University Press . (1971). Objects of Thought. Oxford University Press

Quine, W. V. O. (1960). Word and Object. MIT Press

Rasmussen, J. (2012). Presentists May Say Goodbye to A-properties. Analysis 72: 270-76 
Rayo, A. \& S. Yablo (2001). Nominalism through de-nominalization. Noûs 35: 74-92

Sider, T. (2001). Four-dimensionalism: An Ontology of Persistence and Time. Oxford University Press

Sider, T. (2011). Writing the Book of the World. Oxford University Press (2017). Ross Cameron's The Moving Spotlight. Analysis Reviews 77: 788-99

Skow, B. (2015). Objective Becoming. Oxford University Press

Spolaore, G. \& G. Torrengo: The moving spotlight(s). Inquiry DOI:

10.1080/0020174X.2019.1610046

Tooley, M. (1997). Time, Tense and Causation. Oxford University Press

Williamson, T. (2003). Everything. Philosophical Perspectives 17: 415-65 . (2013). Modal Logic as Metaphysics. Oxford University Press

Zimmerman, D. W. (2008). The Privileged Present: Defending an 'A-Theory' of Time. In T.

Sider, J. Hawthorne, and D. W. Zimmerman (eds).Contemporary Debates in Metaphysics.

Routledge: 211-225 